\title{
Conformity Assessment
}

National Cancer Institute

\section{Source}

National Cancer Institute. Conformity Assessment. NCI Thesaurus. Code C142461.

The means by which regulated products are determined to meet the standards of the European Medicine Agency's Essential Requirements. 